\title{
Do Better Informed Investors Always Do Better? A Buyback Puzzle*
}

\author{
Glenn Boyle \\ Director, Sapere Research Group \\ Wellington, New Zealand \\ and \\ Adjunct Professor \\ Department of Economics and Finance \\ University of Canterbury \\ Christchurch, New Zealand \\ glenn.boyle@canterbury.ac.nz \\ Gerald Ward \\ PhD Candidate \\ Robert H Smith School of Business \\ University of Maryland \\ Maryland, USA \\ geraldward@rhsmith.umd.edu
}

April 5, 2018

* We are grateful for the assistance of many people. Helpful comments on earlier versions of this paper were received from Bob Kieschnick, Helen Roberts, Thijs Van Der Heijden, Gil Aharoni, Lyndon Moore, Bill Schulze, Bob Reed, Andrea Menclova, Bob Woodward, Andy Puckett, David Maslar, seminar participants at Cal State-Fullerton, Canterbury, Massey, Melbourne, Monash, Otago, VUW, and Waikato, and, especially, two anonymous Economic Inquiry referees. Tim Irwin and Seini O'Connor provided valuable feedback and suggestions at a formative stage; Max Bowden, Victor Rolton, Peter Lagan, and Kevin O'Meara answered numerous questions about the New Zealand harness racing industry and its associated yearling auctions; Rohan Boyle and Hao Lei provided essential research assistance funded by the University of Canterbury School of Business and Economics. As always, none of these bear any responsibility for remaining errors and ambiguities. 


\title{
Do Better Informed Investors Always Do Better? A Buyback Puzzle
}

\begin{abstract}
We explore the value of private investment information using data from a singular source: auctions of yearling racehorses. Horse breeders possess superior information about their own horses and have strong financial incentives to buy the best of these back at auction. However, those they repurchase subsequently perform significantly worse on average, earning $30 \%$ less at the racetrack than horses purchased by outsiders. Moreover, this under-performance is concentrated in male horses, despite these being purchased exclusively for racing purposes. These puzzling findings cannot be explained by differences in horse risk or breeder abilities, or by non-financial objectives, or by behavioral or selection biases.
\end{abstract}

JEL classification: G02, G11, G14, L83, D44

Keywords: information; auctions; racehorses; buybacks 


\title{
Do Better Informed Investors Always Do Better? A Buyback Puzzle
}

\author{
A little knowledge is a dangerous thing. \\ Traditional misquotation of Alexander Pope
}

\section{Introduction}

A widely-accepted principle of economics is that the possession of private information is beneficial. As Porter (1995, p1) puts it:

"If one buyer has access to information superior to that of its rivals, such as a more precise signal of the item's worth on a future resale market, informational rents may be obtained."

In a well-known example, Hendricks and Porter (1988) find that more informed bidders in oil and gas lease auctions subsequently earn significantly greater profits than do their less informed competitors. In a different setting, Levitt and Syverson (2008) report evidence that real estate agents use their superior information about housing markets to earn excess returns when they sell their own houses.

In this paper, we offer a counter-example. We examine data from a market that offers uncertain investment payoffs to asymmetrically-informed investors: auctions of yearling standardbred racehorses in New Zealand (NZ). In this setting, horse breeders sell untried colts and fillies to aspiring racehorse owners. Two features are important. First, a number of breeders also race horses on their own behalf and so are both sellers and buyers. Second, only yearlings sold at these auctions become eligible to compete in a subsequent high-stakes (approximately $\$ 1$ million per season) series of races for two- and three-year old horses. As a result, breeders sometimes offer their own horses for sale at auction and then buy them 
back at the same auction, i.e., they pay administrative and auctioneer fees in order to retain the option to enter the horse in races with high prize money if it turns out to be of sufficiently high quality.

At the time of each auction, the horses being sold have not yet appeared on the racetrack, or even commenced training. Investment in such horses is highly risky — many turn out to be be either slow, unmotivated, or unsound. Nevertheless, having been able to observe each horse for at least 12 months between birth and sale date, breeders have private information about every horse they offer for sale - about its ease of movement, paddock behavior, tractability, manners, medical history and other factors that can help predict future racing potential. In principle, they should then be able to exploit this information advantage to obtain superior estimates of fundamental value, and hence repurchase the horses that subsequently perform best, at least on average.

However, using data on 1581 horses sold at auction over a three-year period, we find that horses purchased by their own breeders ("buybacks") have significantly lower average racetrack earnings than do horses bought by outsiders ("non-buybacks"). After controlling for auction price (as an indicator of intrinsic horse quality), and other variables that might affect racetrack success, this negative relationship between performance and the possession of private information is confirmed: on average, buybacks earn approximately $30 \%$ less than non-buybacks, despite purchasers of the former having an information advantage.

Such a puzzling finding invites explanation. We explore the possibility that buybacks are less risky investments, or offer economies of scope, or exist to serve different performance objectives, or incur lower operating or opportunity costs. We ask if breeders who repurchase their own horses have low abilities that mitigate their information advantage, or suffer from common cognitive biases. We also address various statistical issues that might cause buyback under-performance to be spurious. However, none of these potential explanations for buyback under-performance receives much support. 
The association of inferior performance with superior information is an unusual one in economics. In a wide variety of settings (e.g., auction outcomes, corporate investment and control, cost of capital, market microstructure), information is important because it allows rational investors to make better decisions. The results of this paper describe a situation in which investors with more information make seemingly-worse decisions.

In the next section, we describe our data and undertake some preliminary analysis. Section 3 contains our main results, while section 4 considers a variety of possible explanations. We offer some concluding remarks in section 5 .

\section{Data and Preliminary Analysis}

In this section, we first describe the collection of our data and outline some of its properties. We then undertake some preliminary analysis of the difference between buybacks and nonbuybacks.

\subsection{Price and performance data}

We use data from six auctions of standardbred yearlings (i.e., horses that are 12-18 months old) conducted during 2005-2007. In February of each year, there are two separate auctions: the Australasian Classic Yearling Sale (held in Auckland) and the New Zealand Premier Yearling Sale (Christchurch). Together, they provide the bulk of the future racing stock for what is a sizable industry; for example, in 2005 there were 2360 races (i) offering total stakes of approximately $\$ 23$ million and (ii) attracting approximately $\$ 160$ million in betting turnover across the three most popular pools. ${ }^{1}$

In these six auctions, a total of 1741 horses were offered for sale. Of these, we exclude

\footnotetext{
${ }^{1}$ All monetary values are in NZ dollars. For a more detailed description of the NZ standardbred racing industry, see Boyle et al. (2010).
} 
160 from the sample either because they were withdrawn prior to auction (128), or failed to sell (17), or died before reaching racing age (14), or were still racing on the sample cutoff date of 31 July 2016 (1), leaving a final sample of 1581 sales made to 653 unique buyers by 499 unique sellers. $^{2}$

Some summary details regarding these transactions appear in Table 1. The greater number of unique buyers means that average sales per buyer $(2.4$; median $=1.0)$ is smaller than for sellers $(3.2 ;$ median $=2.0)$. In addition, the maximum number of sales by a single seller is 43 , while the busiest buyer purchased 36 yearlings over the three year period covered by our sample. Among sellers, 6.4\% were involved in 10 or more transactions, compared with only $3.5 \%$ of buyers. The smaller representation of buyers at the highactivity end of the transaction distribution is unsurprising, insofar as the racing of horses only rarely constitutes the primary source of a buyer's business or income. By contrast, a greater proportion of sellers are associated with professional breeding companies who sell in significant quantities.

For each yearling sold, we obtained data on auction price, breeder, buyer, sex and name from the website of PGG Wrightson, the auctioneer. Data on subsequent horse ownership, training, and racing performance were hand collected from the Harness Racing New Zealand (HRNZ, the governing body of NZ standardbred racing) website, which contains detailed information, in the InfoHorse section, on the owners, trainers, and performance of every standardbred horse that has raced in NZ since $1985 .^{3}$

\footnotetext{
${ }^{2}$ The NZ racing season runs from 1 August to 31 July, so the youngest horses in the sample (those sold in the 2007 auctions) turned 11 years old the day after the sample cutoff date. The only horse in our sample still actively racing in NZ on that date was a soon-to-be 12 year old non-buyback who, in 198 starts over 9 seasons, had earned $\$ 108,480$. Neither the exclusion of this horse from the sample, or the 14 horses who died young, has any effect on our results.

${ }^{3}$ For the PGG Wrightson data, see http://standardbred.pggwrightson.co.nz/Sales/Results. The HRNZ information can be accessed at http://harness.hrnz.co.nz/gws/ws/r/infohorsews/wsd08x.
} 
Table 1: Sales and Purchases of Yearling Horses

\begin{tabular}{lcc}
\hline & Sellers & Buyers \\
\hline Number of unique agents & 499 & 653 \\
Number of transactions & & \\
Mean & 3.2 & 2.4 \\
Median & 2.0 & 1.0 \\
Maximum & 43 & 36 \\
Distribution & & \\
1 Transaction & 219 & 397 \\
2 Transactions & 120 & 115 \\
3 Transactions & 48 & 49 \\
4 Transactions & 33 & 27 \\
5-9 Transactions & 47 & 42 \\
10-19 Transactions & 22 & 12 \\
20+ Transactions & 10 & 11 \\
\hline \hline
\end{tabular}

As well as organizing the auctions, PGG Wrightson also sponsor a major series of races for two- and three-year old horses, known as the PGG Wrightson NZ Yearling Sales Series, that offers approximately $\$ 1$ million in stakes each year spread over six races. Eligibility for this series - the most valuable available to two- and three-year old horses in NZ - is restricted to horses sold via the Australasian Classic and New Zealand Premier auctions. Although only $2 \%$ of horses sold through these sales subsequently qualify for the associated race series), this arrangement provides an obvious incentive for breeders to offer their best horses for auction and then seek to buy them back.

This feature distinguishes our setting from that of Chezum and Wimmer (1997), who examine United States auctions of thoroughbred yearlings. They find evidence of an adverse selection problem: breeders who also race horses on their own account have an incentive to 
auction only their less promising yearlings while keeping those with the greatest potential at home. Buyers respond by paying lower average prices for the yearlings offered by such breeders. By contrast, the environment we examine has a very different incentive structure: the race eligibility criterion means that breeders who also race horses are incentivized to put their most highly regarded yearlings up for auction and then seek to buy them back.

Prior to the auction, prospective buyers can study the auction catalogue (which contains information on yearling name, breeding, color, sex, and breeder) and are usually able to inspect any horses they are potentially interested in purchasing. At the auction itself, buyers see the horse when it enters the auction ring. Breeders not only have all this information, but have also had the opportunity to observe the horse in various situations (e.g., in the paddock, in the barn, in contact with other horses, traveling) over a period of at least 12 months. ${ }^{4}$ Although we are not aware of any direct evidence that this additional information has predictive power for a horse's future racetrack performance, it appears to be a commonly-held view. For instance, Chezum and Wimmer (1997, p521) note that:

In the roughly one-and-a-half years before the seller takes a yearling to auction, he or she is able to observe how a yearling responds to other yearlings, has access to the yearling's complete medical history, and generally identifies the yearling's temperament. While these factors do not perfectly predict the yearling's future on-track success, they do give the seller an informational advantage.

Similarly, Kirkpatrick (2001) argues that private information on conformation, athleticism and medical history are important determinants of a horse's true value. Auction participants seem to agree: using a small private database on thoroughbred yearlings, Eberhart (2009) reports evidence consistent with Kirkpatrick's claim. In addition, Wimmer and Chezum (2003) find that yearling certification (an auction house quality guarantee that

\footnotetext{
${ }^{4}$ They are not, however, allowed to commence any formal training of these horses.
} 
Table 2: Buyback versus Non-Buyback Purchases of Yearling Horses

\begin{tabular}{lc}
\hline & Buyback Purchases \\
\hline A. Full Sample & $18.8 \%$ \\
B. Auction Year & \\
2005 & $19.9 \%$ \\
2006 & $17.7 \%$ \\
2007 & $19.5 \%$ \\
C. Auction Location & \\
Auckland & $18.8 \%$ \\
Christchurch & $18.9 \%$ \\
\hline \hline
\end{tabular}

essentially communicates the private information of breeders) eliminates the adverse selection discount of Chezum and Wimmer, suggesting that auction participants believe that breeders possess an information advantage.

Table 2 contains information about the breakdown between buyback and non-buyback sales. We initially define a buyback purchase as occurring when a breeder repurchases one of his own horses at auction and subsequently retains it for racing. In our sample, $18.8 \%$ (298) of the horses sold at auction fit this criterion, and this percentage is common to both auction locations. ${ }^{5}$ There is also very little difference across years, with buybacks ranging from a low of $17.7 \%$ in 2006 to a high of $19.9 \%$ in 2005 . Overall, buyback propensity appears to be a systematic phenomenon.

Table 3 provides some summary statistics on price and racetrack performance. The typical yearling sells for slightly less than $\$ 23,000$, with buybacks being approximately $\$ 5400$ cheaper than non-buybacks on average. Variation in price is considerable - from a

\footnotetext{
${ }^{5}$ The 298 buybacks were made by 207 different breeders. Of these, 158 repurchased one of their own horses, 27 bought two, 10 bought three, 7 bought four, 3 bought five, and 1 each bought six and seven respectively.
} 
Table 3: Summary Statistics for Horse Prices and Performance

\begin{tabular}{lcccccc}
\hline & & $\begin{array}{c}\text { Full Sample } \\
(\mathrm{N}=1581)\end{array}$ & & $\begin{array}{c}\text { Buyback } \\
(\mathrm{N}=298)\end{array}$ & $\begin{array}{c}\text { Non-Buyback } \\
(\mathrm{N}=1283)\end{array}$ & \\
& $\begin{array}{c}\text { Mean } \\
{[\text { Median }]}\end{array}$ & Minimum & Maximum & $\begin{array}{c}\text { Mean } \\
\text { [Median }]\end{array}$ & $\begin{array}{c}\text { Mean } \\
{[\text { Median }]}\end{array}$ & $p$-value \\
\hline Price & $\$ 22,932$ & $\$ 1000$ & $\$ 210,000$ & $\$ 18,581$ & $\$ 23,942$ & 0.00 \\
& {$[\$ 15,000]$} & & & {$[\$ 12,500]$} & {$[\$ 16,000]$} & 0.00 \\
Career Earnings & $\$ 22,503$ & $\$ 0$ & $\$ 2,426,765$ & $\$ 12,667$ & $\$ 24,787$ & 0.00 \\
& {$[\$ 2325]$} & & & {$[\$ 1409]$} & {$[\$ 2613]$} & 0.03 \\
Career Return & 1.267 & $\$ 0$ & 111.48 & 0.895 & 1.354 & 0.03 \\
& {$[0.118]$} & & & {$[0.069]$} & {$[0.122]$} & 0.02 \\
Portfolio Career Return & 0.981 & & & 0.682 & 1.742 & \\
\hline \hline
\end{tabular}

Notes: Career Earnings is the horse's lifetime racetrack winnings. Career Return is the horse's lifetime racetrack winnings divided by the auction price, i.e., Career Earnings/Price. Portfolio Career Return is the sum of career earnings for all horses in the relevant sample divided by the sum of their prices. $p$-values for the difference between buybacks and non-buybacks are based on the $t$-test (means) and the van der Waerdan test (medians).

low of $\$ 1000$ to a high of $\$ 210,000$.

Our first, and primary, measure of performance is the horse's career earnings in NZ. In our sample, the average yearling earns a little over $\$ 22,500$ at the racetrack but this reflects considerable variation: career winnings range from $\$ 0$ (the fate of $36.6 \%$ of horses in our sample) to over $\$ 2$ million. Unsurprisingly, the distribution is highly right-skewed: the median horse earns only $\$ 2325$. Career earnings is also strongly correlated with price: the Pearson correlation is $0.19(t$-statistic $=6.01)$, suggesting that price contains useful information about future racing performance.

More interesting is the difference between buybacks and non-buybacks. Surprisingly, the average buyback horse earns little more than $50 \%$ of that earned by its non-buyback counterpart - $\$ 12,667$ versus $\$ 24,787$. The difference in medians is similar - $\$ 1409$ versus \$2613. Breeders apparently repurchase less successful racehorses. 
A horse's career earnings are an indicator of its racing quality, which is of primary importance to yearling buyers who are motivated by the desire to own a "champion" (see, for example, DeGennaro, 2003). However, some auction bidders may have more mundane financial preferences, and even a mediocre racehorse can be a worthwhile investment if bought at a low enough price. As an alternative performance measure, we therefore divide career earnings by auction price to yield an approximate indicator of the return on investment that a horse provides.

Figure 1 shows that these two performance measures are closely related (Pearson correlation $=0.91 ; t$-statistic $=67.6)$ for the sub-sample of horses with positive career earnings. Unsurprisingly, therefore, Table 3 reveals that buybacks also under-perform according to the career return measure — both the mean and median are more than $50 \%$ higher for non-buybacks. Thus, in our sample, a faster horse is typically also a better investment. ${ }^{6}$

Buyback under-performance can be seen even more vividly in Figure 2. For both buybacks and non-buybacks, we sort the data into auction price quintiles and estimate average performance within each quintile. For both performance measures, Figure 2 reveals that the under-performance of breeder buybacks is a feature of the entire price range: in each quintile, buybacks are noticeably less successful than non-buybacks.

Overall, the picture painted by these summary statistics is one of breeders choosing to repurchase horses that subsequently under-perform, despite having information that gives them an advantage in identifying animals that out-perform. However, both career earnings and career return are, from an owner's perspective, only partial measures of horse performance. Ideally, we would also incorporate the ongoing costs of racehorse ownership and any gains from subsequent resale, since both can obviously have a significant effect

\footnotetext{
${ }^{6}$ For the measure of career return relevant to a perfectly-diversified investor (the sum of career earnings for all horses divided by the sum of their prices), a similar pattern applies: 0.981 for the full sample, 0.682 for buybacks, and 1.742 for non-buybacks.
} 


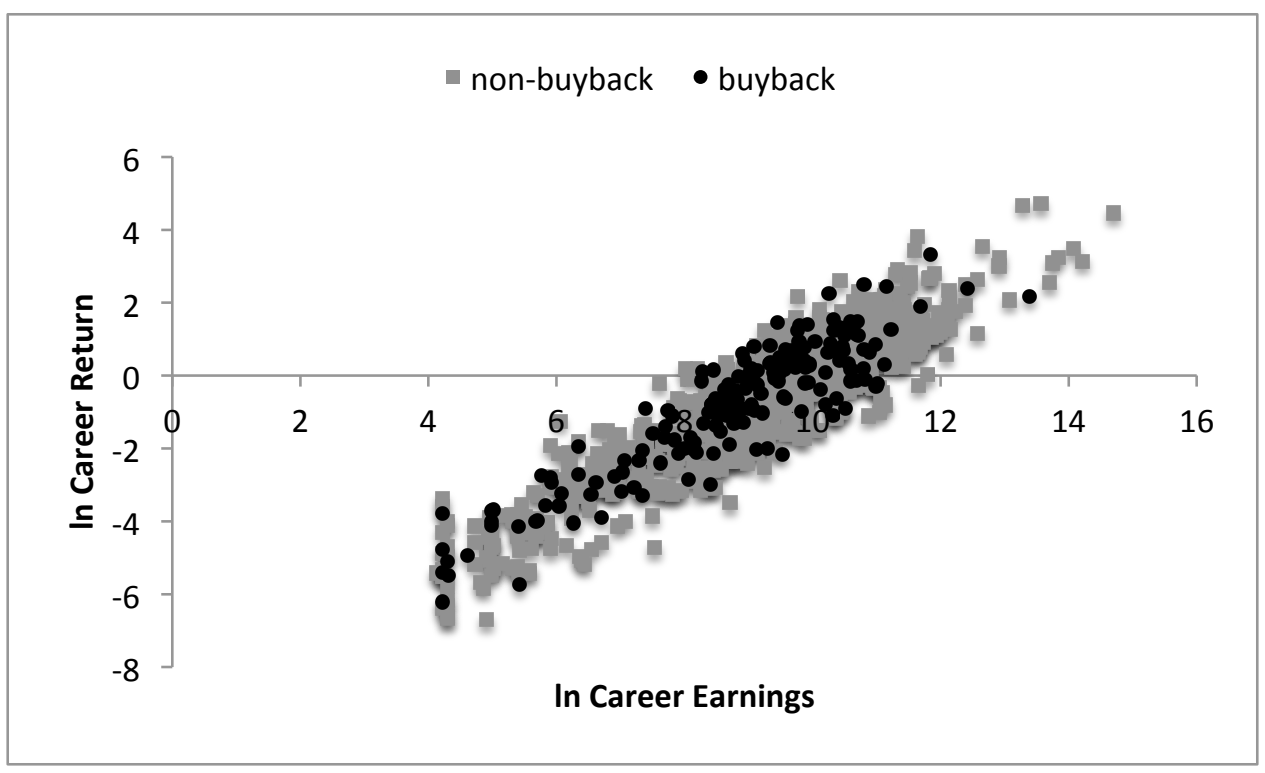

Figure 1: Scatterplot of career earnings and career return performance variables (in natural logs) for the sub-sample of horses with positive earnings.

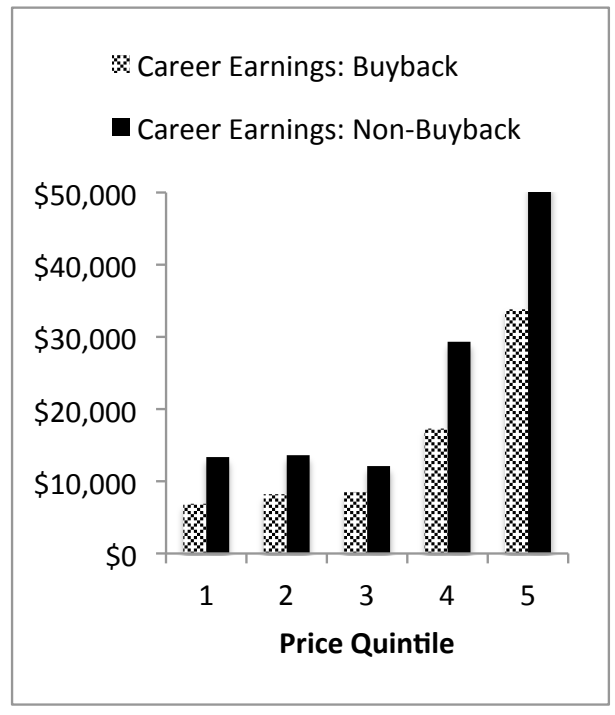

(a)

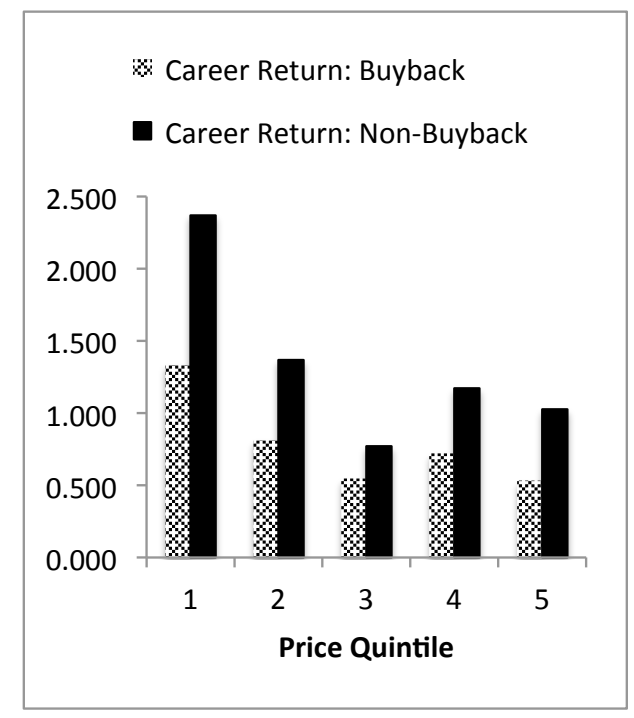

(b)

Figure 2: Performance by Price Quintile. Panel (a) depicts average career earnings sorted from lowest to highest price quintile; Panel (b) depicts average career return sorted from lowest to highest price quintile. 
on the total return to owners. Unfortunately, we have no direct information on either of these variables. To the extent that buybacks are less costly to race, or are more likely to be subsequently sold for a significant sum, this could change our results. In subsequent sections, we attempt to address the resale issue by adjusting our analysis for horses that are exported (section 3.1), or re-sold subsequent to auction (section 4.4.3). We also investigate the cost issue by analyzing horse earnings per season raced (section 4.7.2).

In addition to these considerations, there may be other variables affecting performance that are correlated with the buyback decision; there may also be straightforward explanations for buyback under-performance. We take up the first of these issues in section 3 before proceeding to the second in section 4 .

\subsection{What predicts the likelihood of a buyback?}

Before undertaking a more detailed examination of buyback under-performance, we first address a simpler question: what predicts whether a horse is repurchased by its breeder or not? As well as providing a fuller picture of our data, the answers to such a question have the potential to shed light on potential determinants of the phenomenon in which we are primarily interested: buyback under-performance.

In general, we might expect the likelihood of a horse being a buyback to depend on (i) horse characteristics and (ii) buyer characteristics. We consider several examples of each that are available in our dataset.

Focusing first on horse characteristics, we have already seen (Table 3) that buybacks are associated with a lower average auction price. Our dataset also contains information on horse gender (filly versus colt) and on whether or not a horse is subsequently exported to another country (primarily to Australia or the United States). Both are potentially informative about the buyback decision: fillies may be repurchased in order to ensure future 
breeding stock, while buybacks may in part be motivated by a desire to subsequently onsell the horses to overseas buyers at an attractive price. We therefore create two dummy variables: Filly — set equal to 1 if the horse is a filly (539 observations in our sample) and 0 otherwise; and Export — set equal to 1 if the horse is exported prior to turning four years old (270 observations) and 0 otherwise.

Turning to buyer characteristics, an obvious candidate is the size of the breeding operation selling the horse. Large professional breeders are likely to have incentives that differ from those of small hobby breeders, potentially seeing them repurchase their own horses at a higher or lower frequency. We measure the size of a breeding operation with the variable Breeder Sales — the total number of auction sales made by the horse's breeder during our sample period (see Table 1 for the underlying distribution).

Also, some auction bidders make use of agents acting on their behalf, possibly in order to conceal the bidder's identity and not reveal private information, which would seem to be particularly important for buybacks. We therefore create another dummy variable: Agent — set equal to 1 if the successful auction bidder uses an agent to purchase the horse (117 such occurrences in our sample) and 0 otherwise.

We are also able to obtain information on buyer gender, although this is not entirely straightforward. The auction results list buyer names, but provide no direct indication of gender. In some cases, such as where the buyer is "Mrs Smith", gender is obvious. In other cases, such as where the buyer is "R Smith" or "Robin Smith", things are not so clear. Some buyers are able to be identified via the HRNZ website (if they have some professional involvement in the industry), but this is a minority. Our approach is to create a dummy variable Female Buyer that is set equal to 1 if the horse buyer is listed as "Miss", "Ms", or "Mrs", or has an obviously female first name (e.g., Charlotte), or is otherwise known by us to be female, and 0 otherwise. Where a horse purchase is made jointly, we classify the buyer as female if at least $50 \%$ of the buyers are women. The buyers of 127 horses in our 
Table 4: Summary Statistics for Other Variables

\begin{tabular}{lccccc}
\hline & $\begin{array}{c}\text { All } \\
(\mathrm{N}=1581)\end{array}$ & $\begin{array}{c}\text { Export } \\
(\mathrm{N}=270)\end{array}$ & $\begin{array}{c}\text { Filly } \\
(\mathrm{N}=539)\end{array}$ & $\begin{array}{c}\text { Agent } \\
(\mathrm{N}=117)\end{array}$ & $\begin{array}{c}\text { Female Buyer } \\
(\mathrm{N}=127)\end{array}$ \\
\hline A. Price \& Performance & & & & & \\
Price $(\$)$ & 22,932 & 26,431 & 19,980 & 24,709 & 17,612 \\
& {$[15,000]$} & {$[18,000]$} & {$[13,335]$} & {$[16,500]$} & {$[11,000]$} \\
Career Earnings $(\$)$ & 22,503 & 4203 & 14,966 & 15,685 & 19,902 \\
& {$[2325]$} & {$[0.00]$} & {$[696]$} & {$[5727]$} & {$[782]$} \\
B. Representation & & & & & \\
Full Sample & $100 \%$ & $17.1 \%$ & $34.1 \%$ & $7.4 \%$ & $8.0 \%$ \\
Buyback & $100 \%$ & $13.4 \%$ & $41.9 \%$ & $13.1 \%$ & $20.5 \%$ \\
Non-Buyback & $100 \%$ & $17.9 \%$ & $32.2 \%$ & $6.1 \%$ & $5.1 \%$ \\
p-value & $\mathrm{NA}$ & 0.05 & 0.00 & 0.00 & 0.00 \\
\hline \hline
\end{tabular}

Notes: Panel A reports price and performance means (with medians in square brackets). Panel B shows percentage representations in the various sub-samples. For example, $17.1 \%$ of horses in the full sample are exported prior to their fourth birthday, compared with $13.4 \%(17.9 \%)$ in the buyback (non-buyback) sub-sample. $p$-values are based on a $z$-test of the difference in sample representation between buybacks and non-buybacks.

sample meet these criteria and are classified as female.

Summary statistics for all four dummy variables appear in Table 4. Horses that are exported early in their racing career unsurprisingly earn less on NZ racetracks than other horses, but are sold at a relatively high average price. Although horses purchased via agents also sell for a relatively high average price, they too experience lower-than-average earnings (but higher median earnings). Fillies, and horses purchased by female bidders, sell for relatively low prices and have relatively low average earnings. ${ }^{7}$ Table 4 also reveals that all four characteristics are strongly associated with the buyback decision. Buybacks

\footnotetext{
${ }^{7}$ In addition, breeding operation size has little impact on average price but larger size is associated with mild out-performance. For example, horses offered by breeders with just one sale in our sample sold for an average price of $\$ 22,947$ and had average career earnings of $\$ 19,839$, while horses offered by breeders with more than 20 sales in our sample sold for an average price of $\$ 24,285$ and had average career earnings of $\$ 26,877$. We return to this point in section 4.4.2.
} 
Table 5: Determinants of the Buyback Decision

\begin{tabular}{lcc}
\hline & $(1)$ & $(2)$ \\
\hline Price & $-1.9 \mathrm{E}-06^{* * *}$ & $-1.6 \mathrm{E}-06^{* *}$ \\
& $(6.2 \mathrm{E}-07)$ & $(5.6 \mathrm{E}-07)$ \\
Export & -0.038 & -0.019 \\
& $(0.030)$ & $(0.028)$ \\
Filly & $0.052^{* *}$ & $0.041^{* *}$ \\
& $(0.020)$ & $(0.020)$ \\
Breeder Sales & & $-0.005^{* * *}$ \\
& & $(0.001)$ \\
Agent & & $0.119^{* * *}$ \\
& & $(0.040)$ \\
Female Buyer & & $0.211^{* * *}$ \\
& & $(0.033)$ \\
Pseudo- $R^{2}$ & & 0.07 \\
$p$-value (LR-stat) & 0.02 & 0.00 \\
\hline \hline
\end{tabular}

Notes: Both logit models use 1581 observations and allow for fixed auction year and location effects. All reported coefficients are marginal effects. Numbers in parentheses are robust standard errors clustered at the breeder level. ${ }^{* * *},{ }^{* *}$ and ${ }^{*}$ denote significance at the $1 \%, 5 \%$, and $10 \%$ levels respectively. The last two rows provide McFadden's pseudo- $R^{2}$ and likelihood-ratio probability values respectively.

are more likely to be fillies ( $41.9 \%$ of buybacks versus $32.2 \%$ of non-buybacks), purchased via an agent (13.1\% versus $6.1 \%)$, and to have a female buyer (20.5\% versus $5.1 \%)$, and, more weakly, less likely to be subsequently exported (13.4\% versus $17.9 \%)$.

To incorporate the continuous variables (Price and Breeder Sales), we estimate logit models where the dependent variable is Buyback, which equals 1 if the horse is a buyback and 0 otherwise. The results appear in Table 5 (all reported coefficients are marginal effects); column (1) includes only the horse characteristics as covariates; column (2) adds in buyer characteristics. With the exception of Export, which is not significantly associated with the buyback decision, the results are similar to the univariate findings of Table 4: fillies, and horses purchased via an agent or by a female bidder are more likely to be buybacks (greater probabilities of $0.041,0.119$ and 0.211 respectively). High-priced horses and horses 
bred by large operations are less likely to be buybacks. ${ }^{8}$ In subsequent sections, we consider how each of these variables could potentially contribute to buyback under-performance and assess the extent to which they do.

\section{The Buyback Puzzle: Evidence}

\subsection{Principal result}

We first estimate OLS regression models of the general form:

$$
\text { Career Earnings }=\alpha_{0}+\alpha_{1} \text { Buyback }+\sum_{i} \beta_{i} \text { Control }_{i}+\varepsilon
$$

where each Control $_{i}$ is a variable that potentially influences subsequent horse racetrack performance. We also include dummies for auction location and year. We allow for clustering by estimating robust standard errors at the breeder level. Our primary interest is in the estimate of $\alpha_{1}$, the additional horse winnings associated with breeder repurchases: if the partial information possessed by breeders about their own horses is valuable, then this coefficient should be positive.

In equation (1), the dependent variable is the dollar value of the horse's subsequent racetrack performance, the expected value of which depends on a myriad of factors breeding, size, speed, conformation, heart score, temperament, tractability, and so on. Although these variables are not directly observable to us, their combined importance should be reflected in the horse's auction price (see, for example, Chezum and Wimmer, 1997): horses that command a higher price at auction are expected to be of higher quality and should subsequently perform better on the racetrack.

\footnotetext{
${ }^{8} \mathrm{~A}$ horse sold by a breeder who auctions 10 horses is approximately 0.045 less likely to be a buyback (relative to the full-sample buyback likelihood of 0.188) than a similar horse offered by a breeder who auctions 1 horse. Similarly, a horse sold for $\$ 20,000$ is 0.030 less likely to be a buyback than a horse sold for $\$ 2000$.
} 
Table 6: Horse Performance and Incomplete Information

\begin{tabular}{|c|c|c|c|c|c|c|}
\hline & (1) & (2) & (3) & (4) & (5) & (6) \\
\hline Constant & $\begin{array}{c}19745^{* *} \\
(8662)\end{array}$ & $\begin{array}{c}23532^{\text {*** }} \\
(9016)\end{array}$ & $\begin{array}{c}23211^{* *} \\
(9601)\end{array}$ & $\begin{array}{c}27979^{* * *} \\
(10074)\end{array}$ & $\begin{array}{c}21170^{* * *} \\
(4128)\end{array}$ & $\begin{array}{c}2.095^{* * *} \\
(0.399)\end{array}$ \\
\hline Buyback & $\begin{array}{c}-9641^{* * *} \\
(3198)\end{array}$ & $\begin{array}{c}-10593^{* * *} \\
(3227)\end{array}$ & $\begin{array}{c}-8861^{* * *} \\
(3086)\end{array}$ & $\begin{array}{c}-9691^{* * *} \\
(3112)\end{array}$ & $\begin{array}{c}-9611^{* * *} \\
(3139)\end{array}$ & $\begin{array}{c}-0.515^{* *} \\
(0.206)\end{array}$ \\
\hline Price & $\begin{array}{c}0.469^{* * *} \\
(0.127)\end{array}$ & $\begin{array}{c}0.496^{* * *} \\
(0.129)\end{array}$ & $\begin{array}{c}0.451^{* * *} \\
(0.126)\end{array}$ & $\begin{array}{c}0.476^{* * *} \\
(0.128)\end{array}$ & $\begin{array}{c}0.492^{* * *} \\
(0.137)\end{array}$ & $\begin{array}{r}-1.4 \mathrm{E}-05^{* *} \\
(5.6 \mathrm{E}-06)\end{array}$ \\
\hline Export & & $\begin{array}{c}-24740^{* * *} \\
(3663)\end{array}$ & & $\begin{array}{c}-26097^{* * *} \\
(3979)\end{array}$ & $\begin{array}{c}-26063^{* * *} \\
(3982)\end{array}$ & $\begin{array}{c}-1.379^{* * *} \\
(0.213)\end{array}$ \\
\hline Filly & & & $\begin{array}{c}-9084^{* *} \\
(3618)\end{array}$ & $\begin{array}{c}-11110^{* * *} \\
(3774)\end{array}$ & $\begin{array}{c}-10805^{* * *} \\
(3685)\end{array}$ & $\begin{array}{c}-0.744^{* * *} \\
(0.247)\end{array}$ \\
\hline $\begin{array}{l}\text { Fixed Effects } \\
R^{2}\end{array}$ & Yes & Yes & Yes & Yes & No & Yes \\
\hline$F$-statistic & $5.04^{* * *}$ & $6.57^{* * *}$ & $4.70^{* * *}$ & $6.27^{* * *}$ & $10.33^{* * *}$ & $4.14^{* * *}$ \\
\hline
\end{tabular}

Notes: In columns (1)-(5), the dependent variable is Career Earnings; in column (6) it is Career Return. Fixed effects models include dummies for location and year of auction. Numbers in parentheses are robust standard errors clustered at the breeder level. ${ }^{* * *},{ }^{* *}$ and ${ }^{*}$ denote significance at the $1 \%, 5 \%$, and $10 \%$ levels respectively.

The results from controlling for auction price appear in column (1) of Table 6. Overall explanatory power is low, reflecting the high idiosyncratic risk associated with yearling purchases. Despite this, high-priced yearlings do subsequently perform better, although every additional dollar spent on buying a yearling at auction generates less than $\$ 0.50$ on average. More interestingly, controlling for auction price, and therefore expected horse quality, explains little of the puzzling discrepancy between the earnings of buybacks and non-buybacks: horses that are repurchased by their breeders earn $\$ 9641$ less on average, a finding that is statistically significant at the $1 \%$ level.

Two additional factors potentially complicate this simple relationship. First, as previously discussed in section 2.2, a number of horses in our sample (270) are exported while still relatively young, but our performance measure includes only stakes won while owned 
and trained in NZ. Such horses will obviously appear less successful according to such a measure. Second, female horses (fillies) are often retired early due to having been bought just as much for future breeding reasons as for racetrack performance.

Table 4 confirms that both exports and fillies have considerably lower mean and median earnings than other horses. Moreover, as discussed in section 2.2, buybacks are less likely to be exported than non-buybacks and more likely to be fillies. Motivated by these findings, columns (2)-(5) of Table 6 contain results from including the Export and Filly dummy variables in equation (1). Fillies and horses that are exported early in their racing careers both earn significantly less than average, but this has little effect on the buyback puzzle: the average shortfall is above $\$ 8800$ in all specifications. Setting other variables equal to their sample means, these dollar shortfalls correspond to buyback under-performance of $30 \%$ or more. Column (6) of Table 6 employs career return as the dependent variable and the results are very similar. Buybacks appear to be both inferior horses and inferior investments.

\subsection{Data issues}

Before proceeding further, we wish to be confident that buyback under-performance is not a spurious phenomenon attributable to certain characteristics of our data. We discuss four ways by which this might occur.

\subsubsection{Outliers}

The top-performing horse in our sample (racetrack earnings of over $\$ 2.4$ million) is a nonbuyback, raising the possibility that buyback under-performance is due to the presence of a small number of outliers. To address this concern, we successively remove high-performing horses from the sample and re-estimate equation (1). Specifically, we first remove horses earning more than $\$ 2$ million (1 non-buyback), then those earning more than $\$ 1$ million 
(3 non-buybacks), then those earning more than $\$ 500,000$ (8 non-buybacks, 1 buyback), and finally those earning more than $\$ 250,000$ (13 non-buybacks, 2 buybacks). Note that such a procedure is biased towards eliminating buyback under-performance since it deletes high-earning non-buybacks at a rate significantly greater than their overall appearance in the sample. Despite this, buyback under-performance remains strong in all these cases. For example, when horses with earnings greater than $\$ 500,000$ are excluded, the estimated buyback coefficient is $-\$ 5907(p$-value $=0.0005)$. Buyback under-performance does not seem to be the result of an outlier problem.

\subsubsection{Non-normal performance distributions}

Although outliers may not be an issue, our performance variables are highly right-skewed and the Jacques-Bera test strongly rejects normality (the same is true of the regression residuals in the Table 6 models). Although there is some debate about the importance of non-normality in large samples (see, for example, Lumley et al., 2002), conventional wisdom suggests that standard $t$-statistics may be unreliable. In short, buyback under-performance could be spurious.

With positive-valued data, the standard solution for skewness is to take the natural log. However, this is not feasible here due to the large number of zeros in our performance data. Instead, we adopt the Generalized Linear Model (GLM) approach suggested by Knüpfer et al. (2017) and Santos Silva and Tenreyro (2006). This approach estimates the Poisson regression model:

$$
\text { Career Earnings }=\exp \left(\alpha_{0}+\alpha_{1} \text { Buyback }+\sum_{i} \beta_{i} \text { Control }_{i}+\varepsilon\right)
$$

using a quasi-maximum likelihood estimator with Huber-White standard errors; as discussed by Santos Silva and Tenreyro, this approach produces consistent parameter estimates when the dependent variable is continuous, skewed, non-negative, and contains a 
Table 7: Horse Performance and Incomplete Information: GLM Estimation

\begin{tabular}{|c|c|c|c|c|c|c|}
\hline & (1) & (2) & (3) & (4) & (5) & (6) \\
\hline \multirow[t]{2}{*}{ Constant } & $9.993^{* * *}$ & $10.137^{* * *}$ & $10.137^{* * *}$ & $10.314^{* * *}$ & $10.055^{* * *}$ & $0.922^{* * *}$ \\
\hline & $(0.366)$ & $(0.370)$ & $(0.398)$ & $(0.405)$ & $(0.166)$ & $(0.270)$ \\
\hline \multirow[t]{2}{*}{ Buyback } & $-0.588^{* * *}$ & $-0.628^{* * *}$ & $-0.551^{* *}$ & $-0.576^{* * *}$ & $-0.561^{* * *}$ & $-0.465^{* *}$ \\
\hline & $(0.232)$ & $(0.231)$ & $(0.227)$ & $(0.225)$ & $(0.226)$ & $(0.191)$ \\
\hline \multirow[t]{2}{*}{ Price } & $1.2 \mathrm{E}-05^{* * *}$ & $1.3 \mathrm{E}-05^{* * *}$ & $1.2 \mathrm{E}-05^{* * *}$ & $1.3 \mathrm{E}-05^{* * *}$ & $1.3 \mathrm{E}-05^{* * *}$ & $-1.6 \mathrm{E}-05^{* *}$ \\
\hline & $(1.9 \mathrm{E}-06)$ & $(2.0 \mathrm{E}-06)$ & $(2.0 \mathrm{E}-06)$ & $(2.1 \mathrm{E}-06)$ & $(2.2 \mathrm{E}-06)$ & $(6.5 \mathrm{E}-06)$ \\
\hline \multirow[t]{2}{*}{ Export } & & $-1.950^{* * *}$ & & $-1.991^{* * *}$ & $-1.990^{* * *}$ & $-2.077^{* * *}$ \\
\hline & & $(0.231)$ & & $(0.231)$ & $(0.232)$ & $(0.210)$ \\
\hline \multirow[t]{2}{*}{ Filly } & & & $-0.485^{* * *}$ & $-0.550^{* * *}$ & $-0.544^{* * *}$ & $-0.639^{* * *}$ \\
\hline & & & $(0.193)$ & $(0.193)$ & $(0.190)$ & $(0.171)$ \\
\hline Fixed Effects & Yes & Yes & Yes & Yes & No & Yes \\
\hline Pseudo- $R^{2}$ & 0.06 & 0.12 & 0.08 & 0.14 & 0.13 & 0.27 \\
\hline$p$-value (LR-stat) & 0.00 & 0.00 & 0.00 & 0.00 & 0.00 & 0.00 \\
\hline
\end{tabular}

Notes: Re-estimation of the Table 6 models using GLM with a log link in order to simultaneously allow for skewness and zeros in the Career Earnings and Career Return variables. Numbers in parentheses are Huber-White standard errors. ${ }^{* * *},{ }^{* *}$ and ${ }^{*}$ denote significance at the $1 \%, 5 \%$, and $10 \%$ levels respectively.

non-trivial number of zeros. ${ }^{9}$

The results generated by this approach appear in Table 7 . The overall picture is very similar to Table 6, with buybacks performing significantly worse than non-buybacks. Quantitatively, estimated under-performance is also of a similar magnitude, e.g., the marginal effect for buybacks in column (4) is approximately $-\$ 12,962$, compared to $-\$ 9691$ when estimated by OLS. ${ }^{10}$ Due to the similarity of the results generated by the two estimation methods, we henceforth report only the more easily-interpretable OLS models.

\footnotetext{
${ }^{9}$ More formally, this procedure is known as GLM with a logarithmic link function. For a simple discussion, see Gould (2011).

${ }^{10}$ The approximate marginal effect in column (4) is the buyback coefficient estimate (-0.576) times average career earnings $(\$ 22,503)=\$ 12,962$.
} 


\subsubsection{Fixed year and location effects}

The models reported in columns (1)-(4) of Table 6 include fixed effects for possible variation in the expected performance of horses sold in different years and locations. The downside to this approach is that it assumes the performance-buyback relationship is the same in all cases. To check that the Table 6 results are not driven by a single year or location, we re-estimate the base model (column (4)) for each year and sale location separately. The estimated buyback shortfall is economically large and statistically significant for both locations (average estimate $=-\$ 12,028$; average $t$-statistic $=2.50$ ); the same is true for the 2005 and 2006 years, but not for 2007 (average estimate $=-\$ 10,035$; average $t$-statistic $=$ 2.01). Thus, with the exception of 2007 sales, individual location or year regressions yield a similar degree of buyback under-performance as the full-sample regression.

\subsection{Summary}

To summarize our evidence to this point, after controlling for price, gender, and resale to foreign buyers, and for possible statistical problems, we continue to obtain the result suggested by Table 3 and Figure 2: auction bidders with better information systematically buy horses that subsequently perform worse. That successful auction bidders can be subject to a "winner's curse" is no surprise - see Thaler (1988). What is surprising here is that the curse is greater for the more informed group of investors. This stands in stark contrast to results obtained by other authors. For instance, Hendricks et al. (1987) and Hendricks and Porter (1988) examine the sale of offshore oil and gas tracts by the United States. They find that firms which own tracts adjacent to those being auctioned, and are thus presumably better informed, subsequently achieve significantly higher profits than nonneighbor firms. Similarly, Dionne et al. (2015) show that target firm blockholders, who are presumably better informed about the firm's prospects, earn higher returns than other 
bidders in corporate acquisitions.

In the spirit of these earlier papers, we emphasize that the puzzling feature of our results is not that buyback breeders merely fail to exploit their information advantage. A failure to find any evidence of superior performance by buyback horses could easily be attributed to breeder private information being insufficient to offer them an observable advantage, particularly given the uncertainty about subsequent racehorse performance. Instead, the puzzle is that horses repurchased by their breeders actually perform worse on average. Even if the information possessed by breeders is of epsilon value, we know of no economic theory which suggests that it should result in inferior returns. In the next section, we turn our attention to this issue.

\section{The Buyback Puzzle: Possible Explanations}

Why do investors with an information advantage choose investments that seemingly underperform? In this section, we consider a number of possible explanations for this puzzling phenomenon. First, we ask whether buyback motivation differs between colts and fillies and find that under-performance is unexpectedly concentrated in colt buybacks, thus identifying a further puzzle. Second, we look for differences in risk and skewness between buybacks and non-buybacks, but find no evidence that such differences exist. Third, we investigate whether buyback breeders differ from their contemporaries along a variety of dimensions — ability, preferences and objectives, behavioral biases, and auction bidding strategies that could potentially explain buyback under-performance, but find no evidence that this is the case. Fourth, we consider the possibility that buybacks systematically have lower ongoing costs or receive lower quality inputs, but this too receives no support from the data. Finally, we allow for the possibility that the true opportunity cost faced by buyback breeders is less than the price paid at auction, but this turns out to have only a minor 
effect on the buyback puzzle.

\subsection{Reinvestment by breeders}

One obvious explanation for the observed under-performance of buybacks is suggested by the organizational structure of the breeding industry. Because horses are finite-lived assets, breeding firms must frequently reinvest in their broodmare stocks if they are to continue to operate; that is, they need, at a minimum, to replace their female horses that die or become too old to continue breeding. One simple way of doing so, especially if they wish to retain access to a particular breeding family, is to keep the fillies they breed themselves. However, an additional consideration is that two- and three-year old fillies are able to race primarily against their own sex and thus, if they have sufficient ability, to earn considerable sums at the racetrack by being eligible for the PGG Wrightson series, for example. Thus, breeders who enter both male and female horses in the auctions may use different criteria for their buyback decisions: colts are repurchased based solely on their racing potential, while breeding potential is at least a partial consideration for fillies. Put another way, colts are bought back for income purposes only, while both income and reinvestment considerations are relevant for fillies.

All this suggests that breeders will overlook limited racing potential in a filly if it has strong breeding potential, and hence are more likely to repurchase fillies that subsequently under-perform at the racetrack. Moreover, even if a filly turns out to be a quality racehorse, its breeding potential means that retirement from the racetrack is likely to occur sooner than for a colt of equal ability (breeding opportunities are rare for male horses), and hence will end up with lower career earnings. In short, to the extent that breeder repurchases of their female horses are motivated partly by a need to replenish their breeding stock, the estimate of buyback under-performance is likely to be biased downwards by the inclusion 
Table 8: Do Reinvestment Considerations Explain Buyback Under-Performance?

\begin{tabular}{lcc}
\hline & $(1)$ & $(2)$ \\
\hline Constant & $19871^{* *}$ & $29851^{* * *}$ \\
& $(8673)$ & $(10436)$ \\
Buyback-Colt & $-13373^{* * *}$ & $-18050^{* * *}$ \\
& $(3051)$ & $(4332)$ \\
Buyback-Filly & -4429 & 2899 \\
& $(5451)$ & $(6335)$ \\
Price & $0.473^{* * *}$ & $0.475^{* * *}$ \\
& $(0.128)$ & $(0.128)$ \\
Export & & $-25740^{* * *}$ \\
& & $(3872)$ \\
Filly & & $-15390^{* * *}$ \\
& & $(5069)$ \\
$R^{2}$ & 0.02 & 0.03 \\
$F$-statistic & $4.30^{* * *}$ & $5.82^{* * *}$ \\
\hline \hline
\end{tabular}

Notes: The dependent variable is career earnings. All models include auction year and sales location fixed effects. Numbers in parentheses are robust standard errors clustered at the breeder level. ${ }^{* * *},{ }^{* *}$ and ${ }^{*}$ denote significance at the $1 \%, 5 \%$, and $10 \%$ levels respectively.

of fillies in our buyback variable.

To examine this issue, we re-estimate equation (1) with separate dummies for male and female buybacks. If breeder reinvestment is the cause of the buyback puzzle, then under-performance should be concentrated in the filly repurchases. However, as can be seen in Table 8, distinguishing between male and female buybacks actually exacerbates the puzzle - it is male buybacks that under-perform while female buybacks perform on a par with non-buybacks. When auction price is the only control variable (column (1)), the average shortfall of male buybacks is a statistically significant (at the $1 \%$ level) $-\$ 13,373$; for female buybacks, by contrast, the average shortfall is insignificantly different from zero. When the export and filly controls are added (column (2)), the average male shortfall balloons out to $-\$ 18,050$ while the female equivalent is actually positive (albeit statistically 
insignificant). Clearly, lumping all buybacks, both male and female, together results in an under-statement of buyback under-performance.

Table 8 reveals that there are in fact two buyback puzzles: one, that buyback horses under-perform; two, that this under-performance is restricted to male horses, contrary to what breeder incentives would suggest. Any successful explanation must, therefore, be capable of resolving both puzzles. Because the second puzzle (only male buybacks underperform) is both more puzzling and economically bigger, we henceforth follow a two-step procedure. First, we investigate whether or not a potential explanation is able to resolve the weaker first puzzle; if it does, we then ask whether it can also resolve the stronger second puzzle.

\subsection{Risk}

When two assets are observed to offer different average returns, a natural presumption (at least to economists) is that this reflects a corresponding difference in the risks of the two assets. According to this view, the apparent under-performance of buyback horses can be explained by these horses being less risky investments than non-buybacks.

On initial inspection, such an explanation seems improbable. Asset pricing theory emphasizes the importance of systematic risk, and the probability of a horse turning out to be a good racetrack performer is unlikely to depend on the state of the stockmarket or aggregate consumption. However, as Merton (1987) and Cochrane (2005, p37) emphasize, an asset's unsystematic risk will also be priced when its size renders diversification impractical. As racehorses are lumpy assets that are difficult, and costly, to diversify, total risk (the sum of systematic and unsystematic risk), or dispersion, is potentially relevant.

To estimate career earnings dispersion, we use two non-parametric dispersion measures recommended by statisticians for dealing with highly skewed and non-normal distributions: 
Table 9: Do Differences in Risk Explain Buyback Under-Performance?

\begin{tabular}{lcc}
\hline & Buyback & Non-Buyback \\
\hline Inter-quartile ratio & 8.98 & 6.78 \\
Coefficient of dispersion & 9.79 & 9.55 \\
Coefficient of variation & 3.47 & 4.39 \\
$\operatorname{Pr}($ Career Earnings $=0)$ & 0.40 & 0.36 \\
$\operatorname{Pr}($ Career Earnings $<$ Price $)$ & 0.78 & 0.75 \\
$\operatorname{Pr}\left(\right.$ Career Earnings $<2^{*}$ Price $)$ & 0.89 & 0.86 \\
Skewness & 11.5 & 13.7 \\
\hline \hline
\end{tabular}

Notes: The inter-quartile ratio equals the inter-quartile range divided by the median; the coefficient of dispersion equals the mean absolute deviation from the median divided by the median; the coefficient of variation equals the standard deviation divided by the mean. $\operatorname{Pr}($ Career Earnings $<\mathrm{X})$ is the sample probability that career earnings are less than X. Skewness is the sample estimate of standardized skewness for the career earnings variable.

the inter-quartile ratio (Francis, 2008) and the coefficient of dispersion (Gastwirth, 1982, 1988; Bonett and Seier, 2006). For completeness, we also report the coefficient of variation, although the non-normal nature of the career earnings distribution suggests this measure should be viewed with some caution. In addition, motivated by the evidence of Olsen (1997) that investors care more about downside risk than dispersion, we also estimate the probability of career earnings being (i) equal to zero, (ii) less than the auction price, (iii) less than double the auction price.

However, as Table 9 shows, there is little support for the idea that buyback horses are less risky. Although the coefficient of variation is lower for buybacks (3.47 vs 4.39), both the inter-quartile ratio and the coefficient of dispersion are higher (8.98 vs 6.78 and 9.79 vs 9.55 respectively). Moreover, the downside risk measures are all higher for buybacks.

Buyback under-performance could be due to differences in higher-order risk measures. Racehorses are essentially lottery stocks — investments with a high probability of a small payoff together with a low probability of a very large payoff - and hence have high id- 
iosyncratic skewness. Mitton and Vorkink (2007) and Barberis and Huang (2008) show that certain kinds of investor preferences can lead to a negative relationship between expected returns and idiosyncratic skewness, and Boyer at al. (2009) and Kumar et al. (2011) find evidence consistent with this prediction. This suggests an explanation for the lower average returns of buybacks: that their returns may have greater idiosyncratic skewness than the returns of non-buybacks. However, this is not supported by our data - the career earnings standardized-skewness estimate for buybacks is actually lower (11.5) than that for non-buybacks (13.7).

Overall, we find no evidence that buyback horses offer less risk or more skewness than non-buyback horses; if anything, the reverse is true. Thus, it seems unlikely that the under-performance of buybacks is due to risk or skewness differences.

\subsection{Heterogenous ability}

As Bodnaruk and Simonov (2015) point out, experts can differ along both information and ability dimensions, and that advantages in one area can be offset by disadvantages in the other. In this case, breeders, to the extent that they are breeding experts rather than racing experts, may simply have less ability at identifying promising racehorses than outside buyers, and that this ability disadvantage outweighs their information advantage.

To investigate this possibility, we examine the performance of horses that buyback breeders buy from other breeders. We include in our regression model a new dummy variable (Buyback Buyer) set equal to 1 if the horse is (i) not a buyback and (ii) is bought by a breeder who makes at least one buyback purchase in our sample, and 0 otherwise. In our sample, there are 114 such horses; these are bought by 37 breeders, who also repurchase 46 of their own horses. If breeders who engage in buybacks are truly inferior assessors of horse flesh, then these 114 purchases from other breeders should also perform worse than 
Table 10: Do Differences in Breeder Abilities Explain Buyback Under-Performance?

\begin{tabular}{lcccc}
\hline & $(1)$ & $(2)$ & $(3)$ & $(4)$ \\
\hline Constant & $27202^{* * *}$ & 38906 & $29040^{* *}$ & $12413^{* * *}$ \\
& $(10253)$ & $(23909)$ & $(12300)$ & $(4267)$ \\
Buyback & $-8704^{* * *}$ & $-25770^{*}$ & $-10803^{* *}$ & $-8323^{* * *}$ \\
& $(3327)$ & $(13869)$ & $(5440)$ & $(2708)$ \\
Buyback Buyer & 11239 & & & \\
& $(11303)$ & & & \\
Buyback Seller & & & -2077 & \\
& & & $(5655)$ & \\
Price & & & & \\
& $(0.127)$ & $\left(0.477^{* * *}\right.$ & $0.564^{* * *}$ \\
Export & $-25569^{* * *}$ & $-44540^{* *}$ & $-26083^{* * *}$ & $-22851^{* * *}$ \\
& $(3977)$ & $(17164)$ & $(3976)$ & $(4214)$ \\
Filly & $-11526^{* * *}$ & $-23881^{*}$ & $-11089^{* * *}$ & $-6480^{*}$ \\
& $(3774)$ & $(12308)$ & $(3746)$ & $(3694)$ \\
$N$ & 1581 & 160 & 1581 & 900 \\
$R^{2}$ & 0.03 & 0.09 & 0.03 & 0.05 \\
$F$-statistic & $5.65^{* * *}$ & $2.11^{* *}$ & $5.50^{* * *}$ & $7.24^{* * *}$ \\
\hline \hline
\end{tabular}

Notes: The dependent variable is Career Earnings. Columns (1) and (3) use the full sample. Column (2) uses the sub-sample of 160 horses purchased by breeders who engage in buybacks. Column (4) uses the sub-sample of 900 horses sold by breeders who engage in buybacks. All models include fixed auction year and location effects. Numbers in parentheses are robust standard errors clustered at the breeder level. ${ }^{* * *}$, ** and ${ }^{*}$ denote significance at the $1 \%, 5 \%$, and $10 \%$ levels respectively.

other non-buybacks on average.

However, the data reveal little support for this explanation (column (1) of Table 10). In fact, non-buyback purchases by breeders who also repurchase their own horses out-perform other non-buybacks on average, although the difference is not statistically significant at conventional levels. It appears that buyback breeders as a group have similar ability to other buyers when it comes to identifying promising equine investments, and hence that ability differences cannot explain the buyback puzzle. ${ }^{11}$

\footnotetext{
${ }^{11}$ Of course, this implicitly assumes the 37 breeders who engage in both buybacks and non-buybacks are representative of all 207 breeders undertaking the 298 buybacks. This appears to be the case: average
} 
We also compare the 114 non-buyback purchases by the 37 breeders who also repurchase their own horses with the 46 horses these same breeders repurchase from themselves. Column (2) of Table 10 reveals that the buybacks earn, relative to their breeders' outside purchases, $\$ 25,770$ less on average, although this is only significant at the $10 \%$ level. Thus, even within the small group of breeders who purchase yearlings both from themselves and from others, there is evidence that buybacks underperform.

A second possibility is that the horses produced by buyback breeders in our sample are generally inferior to those offered by other breeders. If this were true, then the negative buyback coefficient in Table 6 would not be evidence of a failure to exploit an information advantage, but instead simply reflect the poorer quality of all horses offered by buyback breeders. Put another way, our results might simply be indicating that breeders buy back the best of a bad bunch.

To test this hypothesis, we create a new dummy variable (Buyback Seller) set equal to 1 if the horse is sold to an outside buyer by a breeder who makes at least one buyback purchase in our sample, and 0 otherwise. In our sample, there are 689 such horses; these are sold by 132 breeders who account for 211 buybacks. If breeders who engage in buybacks produce inferior horses, then these 689 horses they sell to others should also perform worse on average than the horses produced by other breeders.

However, we find no support for this view either (column (3) of Table 10). Although horses sold to outside investors by breeders who also repurchase their own horses do underperform on average, the extent of this is economically small (-\$2077) and statistically insignificant. On average, buyback breeders appear to produce horses of similar ability to other breeders, but then retain a disproportionate number of subsequent under-achievers. career earnings (after adjusting for price and other control variables) of the 46 horses they repurchase differs by $\$ 196$ (statistically insignificant) from the other 252 buybacks, but by $-\$ 12,911$ (significant at the $1 \%$ level) from the 1283 non-buybacks. That is, these 46 horses under-perform similarly to other buybacks. 
In short, inferior breeding ability by breeders who repurchase their own horses cannot explain buyback under-performance.

Finally, we compare the 211 buybacks undertaken by the 132 breeders who also sell to outsiders with the 689 sold by these breeders to others. Column (4) of Table 10 shows that horses sold by this group of breeders to themselves (i.e., the buybacks) earn, relative to their breeders' outside sales, $\$ 8,323$ less on average, which is significant at the $1 \%$ level. As we saw above with buyers, the group of breeders who sell yearlings both to themselves and to others experience buyback under-performance.

\subsection{Alternative breeder objectives}

Our analysis to this point assumes that racehorse investors have an objective function that increases monotonically with expected career earnings. It is possible they pursue some other objective that favors buybacks even at the expense of lower expected career earnings.

\subsubsection{Myopia}

Perhaps horse investors are myopic and so care more about short-term success than about total career earnings. Such a focus might be perfectly rational from the perspective of breeders who engage in buybacks. As previously noted, it is the PGG Wrightson age group races that provide the immediate incentive for breeders to buy their own horses back at auction. Moreover, horses that pay off early provide funding for yearling purchases in subsequent years. For these reasons, buybacks could be selected because they are fastpayback horses, even if they earn less in the long run (which might be discounted very heavily).

To investigate this idea, we change the dependent variable to equal the horse's racetrack winnings as a two- and three-year old only and re-estimate equation (1). As column (1) of Table 11 reveals, this modification effectively eliminates buyback under-performance: the 
estimated difference, while still negative, is now statistically significant at only the $18 \%$ level.

However, we are doubtful that myopic preferences truly resolve the puzzle, for three reasons. First, in contrast to the regression result, the median early earnings of nonbuybacks is approximately five times that of buybacks, a difference that is significant at the $2 \%$ level. Second, the regression result itself is not robust: if, for example, we remove the four horses with the highest levels of early earnings (three non-buybacks, one buyback), the estimated buyback shortfall again becomes significantly negative at the $1 \%$ level. Third, male-buyback under-performance persists (column (2) of Table 11). These contrasting findings reflect the presence in our sample of a single buyback filly with very high early earnings. Comparing medians, or eliminating this horse from the sample, or distinguishing between male and female horses, all neutralize the impact of this horse and buyback underperformance re-emerges.

\subsubsection{Dynamic incentives}

Rather than focussing excessively on the short-term, buyback decisions may instead be motivated by longer-run considerations. For example, breeders may buy back some of their horses mainly in order to retain some racing stock, which then allows them to mingle with, and promote their business to, other horse owners at race meetings (while retaining the option to race for high stakes if the horses prove to be fast enough). According to this view, buyback activity is motivated by marketing factors that are only tangentially related to immediate racetrack success.

Such an objective would require buyback horses to be frequent (if not successful) racers, particularly as young horses. We therefore re-estimate equation (1) using two- and threeyear old race starts as the dependent variable and report the result in column (3) of Table 11. This shows that buyback horses average 1.14 fewer race starts (approximately $25 \%$ 
Table 11: Do Alternative Breeder Objectives Explain Buyback Under-Performance?

\begin{tabular}{|c|c|c|c|c|c|}
\hline Dependent Variable: & $\begin{array}{c}\text { Early } \\
\text { Earnings } \\
(1)\end{array}$ & $\begin{array}{c}\text { Early } \\
\text { Earnings } \\
(2)\end{array}$ & $\begin{array}{c}\text { Race } \\
\text { Starts } \\
(3)\end{array}$ & $\begin{array}{l}\text { Career } \\
\text { Earnings } \\
(4)\end{array}$ & $\begin{array}{l}\text { Career } \\
\text { Earnings } \\
(5)\end{array}$ \\
\hline \multicolumn{6}{|l|}{ Explanatory Variables: } \\
\hline Constant & $\begin{array}{c}9584^{* * *} \\
(3175)\end{array}$ & $\begin{array}{c}10559^{* * *} \\
(3298)\end{array}$ & $\begin{array}{c}4.339^{* * *} \\
(0.449)\end{array}$ & $\begin{array}{c}26303^{* *} \\
(11256)\end{array}$ & $\begin{array}{c}28299^{* * *} \\
(10184)\end{array}$ \\
\hline Buyback & $\begin{array}{l}-2998 \\
(2237)\end{array}$ & & $\begin{array}{c}-1.142^{* * *} \\
(0.384)\end{array}$ & $\begin{array}{c}-11652^{* * *} \\
(4094)\end{array}$ & \\
\hline Buyback-Colt & & $\begin{array}{c}-7349^{* * *} \\
(1650)\end{array}$ & & & \\
\hline Buyback-Filly & & $\begin{array}{c}3556 \\
(5782)\end{array}$ & & & \\
\hline Buyback-Resale & & & & & $\begin{array}{c}-9115^{* * *} \\
(3145)\end{array}$ \\
\hline Price & $\begin{array}{c}0.270^{* * *} \\
(0.795)\end{array}$ & $\begin{array}{c}0.270^{* * *} \\
(0.794)\end{array}$ & $\begin{array}{c}5.3 \mathrm{E}-05^{* * *} \\
(8.7 \mathrm{E}-06)\end{array}$ & $\begin{array}{c}0.474^{* * *} \\
(0.128)\end{array}$ & $\begin{array}{c}0.471^{* * *} \\
(0.129)\end{array}$ \\
\hline Export & $\begin{array}{c}-9681^{* * *} \\
(1838)\end{array}$ & $\begin{array}{c}-9495^{* * *} \\
(1766)\end{array}$ & $\begin{array}{c}-2.983^{* * *} \\
(0.338)\end{array}$ & $\begin{array}{c}-26197^{* * *} \\
(3984)\end{array}$ & $\begin{array}{c}-26191^{* * *} \\
(4002)\end{array}$ \\
\hline Filly & $\begin{array}{l}-892.8 \\
(2019)\end{array}$ & $\begin{array}{l}-3121 \\
(2664)\end{array}$ & $\begin{array}{l}-0.424 \\
(0.358)\end{array}$ & $\begin{array}{c}-11561^{* * *} \\
(3801)\end{array}$ & $\begin{array}{c}-11072^{\text {*** }} \\
(3743)\end{array}$ \\
\hline Breeder Sales & & & & $\begin{array}{c}171.0 \\
(202.5)\end{array}$ & \\
\hline Breeder Sales*Buyback & & & & $\begin{array}{c}317.7 \\
(408.4)\end{array}$ & \\
\hline$R^{2}$ & 0.03 & 0.04 & 0.07 & 0.03 & 0.03 \\
\hline$F$-statistic & $8.15^{* * *}$ & $7.58^{* * *}$ & $16.6^{* * *}$ & $4.98^{* * *}$ & $6.26^{* * *}$ \\
\hline
\end{tabular}

Notes: All models allow for fixed auction time and location effects. Numbers in parentheses are robust standard errors clustered at the breeder level. ${ }^{* * *},{ }^{* *}$ and ${ }^{*}$ denote significance at the $1 \%, 5 \%$, and $10 \%$ levels respectively. 
less) than non-buybacks. ${ }^{12}$ Breeders apparently repurchase horses that are not only poorer performers at the racetrack, but also set foot on it less often.

Another possibility is that, in order to preserve market share, professional breeders respond to a perceived need to maintain a reputation for both quality and quantity of auction offerings. This could provide an incentive for strategic behavior: offer a significant number of horses for auction, but then discreetly repurchase those they believe to be of low ability. Under this policy, a desire for repeat business sees breeders auction and then repurchase horses that it would be cheaper in the short-term to leave at home. Such a policy effectively selects low-ability horses as buybacks, potentially explaining buyback under-performance.

This scenario implies that buyback under-performance should be more prevalent among buybacks undertaken by professional breeders, since repeat business incentives matter less to hobby or amateur breeders. We therefore include Breeder Sales (see section 2.2) in our regression model and interact it with the buyback dummy. If breeder reputational concerns drive buyback under-performance, then the buyback dummy coefficient should become much closer to zero while the coefficient for the interaction term should be negative. However, this is not the case (column (4) of Table 11): the absolute value of average under-performance actually rises (to \$11652) while the interaction coefficient estimate is essentially zero. It therefore seems unlikely that buyback under-performance is due to reputational concerns on the part of professional breeders.

\subsubsection{Capital gains}

We have defined buybacks as auction repurchases that breeders retain for racing and are not on-sold post-auction. In practice though, some breeder repurchases of their own horses could be undertaken with the intention of re-selling these horses privately at a higher price

\footnotetext{
${ }^{12}$ Over a full career, the absolute difference in starts is even greater, although less precisely estimated.
} 
(especially as they now have the added attraction of being qualified for the PGG Wrightson

series). Such post-auction behavior could cause our results to over-state the extent of buyback under-performance. For example, this might arise if there were a selection bias in our data - buybacks with the greatest promise are most easily on-sold, leaving breeders in possession of less-promising types.

To address this issue, we redefine the buyback variable (Buyback-Resale), setting it equal to 1 if the horse is repurchased by its breeder when sold at auction, regardless of whether it is then retained for racing by the breeder or subsequently on-sold prior to beginning a racing career. This results in a further 50 horses being categorized as buybacks. These horses do perform somewhat better than the buybacks retained for racing, but the difference is small: average career earnings of $\$ 15,580$ for the on-sales compared to $\$ 12,667$ for those retained (difference $p$-value $=0.49$ ). The last column of Table 11 confirms that this broader definition of buybacks leaves the under-performance phenomenon intact: the estimated average shortfall is $\$ 9115$, statistically significant at the $1 \%$ level. $^{13}$

\subsection{Behavioral biases}

\subsubsection{Over-confidence}

Does buyback under-performance represent irrational over-buying by breeders? One obvious mechanism is overconfidence: the possession of private information may engender a level

\footnotetext{
${ }^{13}$ As a referee pointed out to us, secondary market purchases of buybacks could be particularly attractive to financially-constrained buyers, for whom early-career earnings are most important. This suggests that, after adjusting the buyback variable to account for on-selling, buyback under-performance should be less apparent in early-career earnings. However, regressing Early Earnings on Buyback-Resale yields results that are virtually identical to those discussed in section 4.4.1: although overall buyback under-performance disappears (coefficient estimate $=-3100 ; p$-value $=0.14$ ), this result is not robust, and male buyback underperformance remains strong (coefficient estimate $=-6908 ; p$-value $=0.00$ )
} 
of confidence that is not justified by the information's imperfect nature, and consequently result in sub-optimal decisions. A large psychology literature documents a link between information and overconfidence. For example, Fleisig (2011) finds that the provision of poor information has the same positive impact on subject confidence as good information, despite the latter being associated with significantly better performance. Similarly, Arkes et al. (1986) report that subject confidence rises with information, but performance declines, i.e., overconfidence increases. Many other studies obtain comparable results, e.g., Oskamp (1965), Hall et al. (2007) and Tsai et al. (2008). Moreover, overconfidence appears to be greatest in situations where there is high residual uncertainty, e.g., Griffin and Tversky (1992), Hayward et al. (2006). In addition, economics research has demonstrated the deleterious impact of overconfidence on asset purchase decisions, e.g., Daniel et al. (1998), Barber and Odean $(1999,2001)$. Together, these various lines of enquiry suggest that additional information raises investor confidence, but that this confidence may be misplaced if the information is incomplete, and that the resulting over-confidence leads to inferior investment decisions. In our setting, this implies a scenario in which breeders over-estimate the precision of their information regarding their own horses, which in turn leads them to disproportionately buy back horses that subsequently perform poorly.

To test this hypothesis, we require a proxy for overconfidence that is available in our data. Barber and Odean (2001) and Levi et al. (2014) find that males typically suffer more from overconfidence than females, so we classify yearling purchases according to the buyer gender variable (Female Buyer) described in section 2.2. If buyback under-performance is due to breeder over-confidence, and if our gender variable is a reasonable proxy for overconfidence, then under-performance should be less apparent in buybacks undertaken by female breeders.

To test this, we estimate a standard difference-in-difference specification of equation (1) that includes the gender variable. However, this reveals (column (1) of Table 12) that 
buybacks by female breeders actually do worse on average (by \$3729) than buybacks by male breeders, although the difference is not statistically significant. ${ }^{14}$

\subsubsection{Over-exuberance}

Another possible form of over-confidence is over-exuberance in the auction process itself. Perhaps buyback breeders are irrational auction participants, bidding too often or for too long when their own stock enters the auction ring, thus resulting in the repurchase of too many slow or over-priced horses. One way of investigating this idea is to compare buyback purchases where the breeder is the auction bidder with buyback purchases conducted by an agent acting on behalf of the breeder/bidder. If buyback under-performance is partly due to over-exuberant bidding by buyback breeders, then the under-performance should be less marked in cases where an agent is used.

To test this hypothesis, we estimate a difference-in-difference specification that interacts Buyback with the Agent dummy introduced in section 2.2 (of the 117 yearling purchases undertaken via an agent, 39 are buybacks). However, as can be seen in column (2) of Table 12, we find no evidence for the view that buyback under-performance is attributable to poor auction strategies by breeders who engage in buybacks. Buyback horses purchased using an agent actually perform worse than those obtained through the breeder bidding on his own behalf, although the difference is statistically insignificant.

\footnotetext{
${ }^{14}$ We also experiment with an alternative characterization where a buyer is defined as female if and only if all members of the buyer group are female (rather than $50 \%$ female), but this yields similar results. In addition, we try two other proxies for over-confidence. First, whether or not the buyer is a professional trainer, whose additional knowledge may render them excessively confident. Second, whether or not the yearling has been nominated for another race series that requires periodic entry fees — not being nominated would indicate a lack of confidence in the horse's potential. However, neither of these are related to buyback under-performance in our data.
} 
Table 12: Does Over-Confidence or Over-Exuberance Explain Buyback UnderPerformance?

\begin{tabular}{|c|c|c|}
\hline & (1) & $(2)$ \\
\hline Constant & $\begin{array}{c}27822^{* * *} \\
(10252)\end{array}$ & $\begin{array}{c}28256^{* * *} \\
(10237)\end{array}$ \\
\hline Buyback & $\begin{array}{c}-9451^{* * *} \\
(3534)\end{array}$ & $\begin{array}{c}-8975^{* * *} \\
(3640)\end{array}$ \\
\hline Price & $\begin{array}{c}0.477^{* * *} \\
(0.129)\end{array}$ & $\begin{array}{c}0.480^{* * *} \\
(0.132)\end{array}$ \\
\hline Export & $\begin{array}{c}-26024^{* * *} \\
(3992)\end{array}$ & $\begin{array}{c}-26113^{* * *} \\
(3987)\end{array}$ \\
\hline Filly & $\begin{array}{c}-11212^{* * *} \\
(3752)\end{array}$ & $\begin{array}{c}-11010^{* * *} \\
(3731)\end{array}$ \\
\hline Female Buyer & $\begin{array}{c}3536 \\
(12460)\end{array}$ & \\
\hline Female Buyer*Buyback & $\begin{array}{c}-3729 \\
(13694)\end{array}$ & \\
\hline Agent & & $\begin{array}{c}-6692^{*} \\
(3883)\end{array}$ \\
\hline Agent*Buyback & & $\begin{array}{l}-1846 \\
(7306)\end{array}$ \\
\hline$R^{2}$ & 0.03 & 0.03 \\
\hline$F$-statistic & $4.88^{* * *}$ & $4.94^{* * *}$ \\
\hline
\end{tabular}

Notes: The dependent variable is Career Earnings. All models allow for fixed auction year and location effects. Numbers in parentheses are robust standard errors clustered at the breeder level. ${ }^{* * *},{ }^{* *}$ and ${ }^{*}$ denote significance at the $1 \%, 5 \%$, and $10 \%$ levels respectively.

\subsubsection{Emotional attachment}

We also consider the possibility that buyback under-performance is due not to over-confidence, but is instead the result of breeders succumbing to an emotional attachment to their own horses. In other words, rather than letting horses they know have limited potential head off to an uncertain future, breeders prefer to take them home. According to this view, 
buyback under-performance is in line with breeders' expectations, and it is precisely these low expectations that motivate buybacks.

Since any such attachment effect is likely to be considerably more powerful for smallerscale, hobby or amateur breeders than for large, professional breeding operations, an obvious line of investigation is to test whether buyback under-performance is less marked among horses repurchased by professional breeders. But as we have already seen (Table 11), this is not the case: buyback under-performance is similar in both large and small breeding operations.

\subsection{Breeder bidding strategies}

Breeder bidding strategies could contribute to buyback under-performance via the information it signals to potential buyers. If the signalling is honest, bidding on one's own yearlings potentially reveals positive information to outside buyers. That is, outside buyers who observe breeders bidding on their own horses might implicitly "learn" about the breeders' private information. ${ }^{15}$ Then there are two possible responses. First, outside buyers are encouraged to bid more aggressively and bid the horse price up. Second, outside buyers are scared off because they fear having to pay too high a price.

Neither of these seems likely to explain buyback under-performance. With respect to the first response, positive information about a horse can be concealed by employing a bidding agent, but section 4.5.2 above shows that such repurchases are associated with the same level of buyback under-performance. Moreover, while forcing buyback breeders to

\footnotetext{
${ }^{15}$ We are doubtful that much learning of this type can actually occur in practice. The auctions take place in a large warehouse/barn area containing hundreds of people, and most yearlings are in the sales ring for no more than 30 seconds. Based on conversations with industry participants, and our own observations, we think most auction participants would have difficulty identifying a bidder as the horse's breeder, or have time to act on that information.
} 
pay a higher repurchase price could potentially explain under-performance as an investment (lower Career Return), it cannot explain why buybacks are also poorer horses (lower Career Earnings). Also, such an explanation is incapable of explaining the second buyback puzzle: if breeder bidding reveals private information about female horses, then it should also reveal private information about male horses, but, as we have seen, buyback under-performance is concentrated in the latter group.

Turning to the second possible response, eliminating outside buyers means breeders face less competition for their buybacks. But this should enable buyback breeders to concentrate their efforts on those they believe to have the greatest ability and to repurchase such horses at a lower price, i.e., buybacks should out-perform.

However, it is also possible that signalling could be misleading or incomplete. For example, breeders may bid on their own horses in the hope of creating price support and eliciting additional outside-bidder demand. ${ }^{16}$ Then, in those cases where outside buyers recognise that the quality signal is false and fail to bid, breeders are left holding the baby. Alternatively, optimal selling behaviour may require breeders to consistently bid on their horses (see, for example, Bulow and Roberts, 1989). If outsiders have additional relevant information about horse quality that is independent of breeder information, then buybacks will typically occur when outsider information indicates low quality, resulting in little outside bidding interest. In both these cases, buybacks can disproportionately occur among low-quality horses that subsequently under-perform.

If either phenomenon is present in our data, then we would expect to see buyback under-performance concentrated among low-price horses: outsiders will not bid very much on horses they believe to be of low quality, and so horses that attract little or no interest (i.e., those that breeders end up with as buybacks under either of these strategies) are unlikely to be associated with high prices. However, although buybacks do sell for lower

\footnotetext{
${ }^{16}$ This is sometimes known as shill bidding. See, for example, Chakraborty and Kosmopoulou (2004).
} 
prices on average (see Table 3), our data do not support the idea that buyback underperformance is the result of this kind of selection bias. For example, splitting the sample into price $>$ median and price $\leq$ median groups sees buyback under-performance appearing similarly in both. In the low-price group, the buyback coefficient estimate is -4959 ( $p$-value $=0.03)$; in the high-price group, it is $-15296(p$-value $=0.01)$. Similarly, interacting the auction price with the buyback dummy in the full-sample regression model also has little effect: the buyback coefficient estimate is $-10094(p$-value $=0.04)$ while the coefficient estimate on the interaction variable is small (0.021) and statistically insignificant ( $p$-value $=0.95)$. In summary, buyback under-performance is not just a low-price phenomenon, and thus seems unlikely to be the result of bidding strategies by breeders.

\subsection{Input costs and quality}

\subsubsection{Economies of scope}

Once purchased, an important determinant of horse performance is the quality of training it is given. Breeders who repurchase their own horses may also be tempted to realize economies of scope by doing their own training rather than entrusting this task to a specialist trainer. Alternatively, breeders may be tied in to a particular training establishment for business reasons that are unrelated to training quality. In either case, buyback horses could receive inferior training, and hence under-perform.

To assess this idea, we proxy for trainer quality using a statistic, commonly used in the industry to rank trainers and drivers, that measures the regularity with which the horse finishes in a position that pays a significant stake to owners:

$$
\frac{9 \times \text { number of firsts }+5 \times \text { number of seconds }+3 \times \text { number of thirds }}{9 \times \text { number of races during season }} .
$$

The "rewards" (9, 5 and 3$)$ to finishing first, second and third respectively represent a 
longstanding industry convention about the relative merits of these placings. ${ }^{17}$ For each trainer of a horse in our sample, we calculate the average of this ratio over the five seasons prior to the horse's auction date. ${ }^{18}$ For buybacks, mean trainer quality ratio is 0.20 and the median is 0.19 ; for non-buybacks, the corresponding statistics are 0.21 and 0.22 respectively. Although economically small, both differences are statistically significant at the $2 \%$ level or better, consistent with buybacks receiving inferior training on average and suggesting that trainer quality could indeed be an important omitted variable. However, when we include the trainer quality proxy in our regression model (first column of Table 13), buyback underperformance persists (estimated shortfall $=-\$ 9931 ; p$-value $=0.03$ ). Differences in the quality of training cannot explain buyback under-performance.

\subsubsection{Operating costs}

Career earnings are a measure of gross returns to owners that take no account of the costs incurred. If buybacks are less costly to own, then buyback under-performance could be illusory.

Unfortunately, as noted in section 2.1, our available data contain no information on the ongoing costs of racehorse ownership, e.g., food, veterinary bills, training fees, transport costs. Nevertheless, their total value is likely to be closely related to the length of a horse's racing career. For a given price, a horse that wins $\$ 50,000$ in a career lasting one season will generally provide a much higher net return to owners than one that earns the same amount over five seasons. Since buybacks have shorter racing careers than non-buybacks

\footnotetext{
${ }^{17}$ This convention is based on unpublished 1948 work by two New York teachers named Haswell and Mead. For more details, see Boyle et al. (2010).

${ }^{18}$ For horses that changed trainer at some point, we employ a time-weighted average of the trainer quality ratio. 532 horses in our sample have no recorded trainer, reducing the sample size to 1049 . None of the eliminated 532 ever started a race, suggesting they either showed insufficient ability to justify expenditure on training fees or suffered a career-ending injury prior to entering training.
} 
Table 13: Do Differences in Input Costs or Quality Explain Buyback Under-Performance?

\begin{tabular}{lcc}
\hline Dependent Variable: & $\begin{array}{c}\text { Career } \\
\text { Earnings }\end{array}$ & $\begin{array}{c}\text { Earnings } \\
\text { Per Season }\end{array}$ \\
\hline Explanatory Variables: & & \\
Constant & 9580 & $7815^{* * *}$ \\
& $(14319)$ & $(2124)$ \\
Buyback & $-9931^{* *}$ & $-2312^{* * *}$ \\
& $(4473)$ & $(922.4)$ \\
Price & $0.387^{* *}$ & $0.135^{* * *}$ \\
& $(0.161)$ & $(0.031)$ \\
Export & $-37856^{* * *}$ & $-6297^{* * *}$ \\
& $(6623)$ & $(945.9)$ \\
Filly & $-13492^{* *}$ & $-2089^{* * *}$ \\
& $(5714)$ & $(976.1)$ \\
Trainer Quality & $163297^{* * *}$ & \\
& $(41305)$ & \\
$R^{2}$ & & \\
$F$-statistic & 0.04 & 0.04 \\
$N$ & $5.00^{* * *}$ & $8.65^{* * *}$ \\
\hline \hline
\end{tabular}

Notes: All models allow for fixed auction time and location effects. Numbers in parentheses are robust standard errors clustered at the breeder level. ${ }^{* * *},{ }^{* *}$ and ${ }^{*}$ denote significance at the $1 \%, 5 \%$, and $10 \%$ levels respectively.

on average $(1.487$ seasons versus $1.688 ; p$-value $=0.04)$, their true respective performances may be closer than is captured by career earnings alone.

To assess this idea, we create a new measure of performance: Earnings Per Season, equal to Career Earnings divided by the number of seasons in which the horse raced (or zero if the horse never raced). This alternative measure downgrades the weight accorded to horses with long careers (and hence high operating costs) and upgrades that given to horses with short careers (low operating costs). The mean value of Earnings Per Season in our sample is $\$ 4507$ for buybacks and $\$ 7463$ for non-buybacks, a difference that is significant at the $1 \%$ level. Similarly, the corresponding medians are $\$ 1011$ and $\$ 1443$, a difference 
that is significant at the $4 \%$ level. Turning to our regression model, the second column of Table 13 shows that such differences persist after controlling for other variables: the average Earnings Per Season shortfall for buybacks is $-\$ 2312(p$-value $=0.01) .{ }^{19}$ Thus, it appears that buybacks also provide inferior net returns to owners: buyback under-performance is not because of lower costs associated with owning buybacks. ${ }^{20}$

\subsection{Divergence between price and opportunity cost}

Thus far, we have implicitly assumed that the winning auction price represents the true opportunity cost to the successful bidder. But in the case of buybacks, the winning bidder is only out of pocket by an amount equal to $10 \%$ (the auctioneer commission rate) of the price, since the remaining $90 \%$ is paid to himself. This raises the possibility that the price paid for buybacks is an upwardly-biased estimate of future horse performance, which could therefore explain the under-performance we observe.

Whether this is the case depends in the first place on the competitiveness of auction bidding. If the breeder is the only bidder, then engaging in a buyback forgoes no other comparable bid and the true cost faced by the breeder-buyer is only $10 \%$ of the official price. In this case, auction price over-estimates the breeder's cost of purchase, and hence the horse's expected performance. As a result, our regression analysis will be biased towards

\footnotetext{
${ }^{19}$ If horses with zero starts are excluded, the results are similar: the buyback coefficient estimate is $-\$ 3541(p$-value $=0.05)$.

${ }^{20} \mathrm{~A}$ related measure is earnings per start: career earnings divided by the number of races in which the horse competed. However, because the costs of food, training and veterinary care over a given time period are incurred regardless of the number of times a horse starts during that period, racing frequency is a noisy measure of costs - a horse that races 40 times over 5 seasons will cost its owners almost 5 times more than a horse that races 40 times in just 1 season. Nevertheless, the results from using earnings per start are similar: the mean value in our sample is $\$ 1495$ for buybacks and $\$ 2069$ for non-buybacks, a difference that is significant at the $3 \%$ level.
} 
finding buyback under-performance.

To address this issue, we require, for buyback horses, a variable that equals auction price if the auction is competitive and $10 \%$ of the price if it is not. ${ }^{21}$ Obviously, this requires distinguishing between competitive and non-competitive auctions. Unfortunately, our data do not contain any information on the number of bids each horse attracts, or any other indicator of bidding competitiveness. Nevertheless, it seems reasonable to presume that low winning prices indicate a less competitive bidding process, since a prospective buyer will succeed with a low bid only if there are no other bidders willing to offer more. Similarly, a high price is likely to indicate a competitive auction, since few bidders will choose to offer a higher price than necessary to win the auction. This suggests:

$$
\text { Opportunity Cost } \_X= \begin{cases}\text { Price, } & \text { if horse is a Non-Buyback } \\ \text { Price, } & \text { if horse is a Buyback and Price } \geq X \\ \text { Price } / 10, & \text { if horse is a Buyback and Price }<X\end{cases}
$$

The choice of $X$ is arbitrary, so we experiment with three alternative values: $X=\$ 5000$ (approximately the 5 th percentile of the auction price distribution), $X=\$ 10,000$ (approximately the 25th percentile), and $X=\$ 20,000$ (approximately the 55th percentile).

As is apparent from columns (1) and (2) of Table 14, this adjustment has little effect on estimated buyback under-performance for $X=\$ 5000$ or $X=\$ 10,000$ : in both cases, the average shortfall remains economically large and statistically significant at the $1 \%$ level. Increasing $X$ to $\$ 20,000$ has a bigger effect: the average shortfall falls to $\$ 6387$ and is significant only at the $10 \%$ level. In principle, it seems that recognizing the true opportunity costs involved in buybacks can at least partly explain buyback under-performance.

\footnotetext{
${ }^{21}$ As bidding follows an English auction process, the breeder's winning bid in a competitive auction is likely to be only marginally greater than the highest bid from an outsider, and hence closely approximate the true opportunity cost.
} 
Table 14: Does a Divergence Between Price and Opportunity Cost Explain Buyback UnderPerformance?

\begin{tabular}{|c|c|c|c|c|}
\hline & (1) & $(2)$ & (3) & (4) \\
\hline Constant & $\begin{array}{c}28001^{* * *} \\
(10074)\end{array}$ & $\begin{array}{c}28180^{* * *} \\
(10072)\end{array}$ & $\begin{array}{c}28126^{* * *} \\
(10085)\end{array}$ & $\begin{array}{c}30002^{* * *} \\
(10442)\end{array}$ \\
\hline Buyback & $\begin{array}{c}-9579^{* * *} \\
(3122)\end{array}$ & $\begin{array}{c}-8621^{* * *} \\
(3208)\end{array}$ & $\begin{array}{c}-6387^{*} \\
(3498)\end{array}$ & \\
\hline Export & $\begin{array}{c}-26109^{* * *} \\
(3981)\end{array}$ & $\begin{array}{c}-26112^{* * *} \\
(3980)\end{array}$ & $\begin{array}{c}-26123^{* * *} \\
(3982)\end{array}$ & $\begin{array}{c}-25765^{* * *} \\
(3874)\end{array}$ \\
\hline Filly & $\begin{array}{c}-11109^{* * *} \\
(3774)\end{array}$ & $\begin{array}{c}-11096^{* * *} \\
(3773)\end{array}$ & $\begin{array}{c}-11075^{* * *} \\
(3769)\end{array}$ & $\begin{array}{c}-15417^{* * *} \\
(5068)\end{array}$ \\
\hline Opportunity Cost_5K & $\begin{array}{c}0.475^{* * *} \\
(0.128)\end{array}$ & & & \\
\hline Opportunity Cost_10K & & $\begin{array}{c}0.469^{* * *} \\
(0.127)\end{array}$ & & \\
\hline Opportunity Cost_20K & & & $\begin{array}{c}0.469^{* * *} \\
(0.128)\end{array}$ & $\begin{array}{c}0.469^{* * *} \\
(0.128)\end{array}$ \\
\hline Buyback-Colt & & & & $\begin{array}{c}-14866^{* * *} \\
(4101)\end{array}$ \\
\hline Buyback-Filly & & & & $\begin{array}{c}6406 \\
(7048)\end{array}$ \\
\hline$R^{2}$ & 0.03 & 0.03 & 0.03 & 0.03 \\
\hline$F$-statistic & $6.27^{* * *}$ & $6.25^{* * *}$ & $6.30^{* * *}$ & $5.85^{* * *}$ \\
\hline
\end{tabular}

Notes: The dependent variable is Career Earnings. Opportunity Cost_X equals Price/10 if the horse is a buyback costing less than $\$ \mathrm{X}$, otherwise it equals Price. All models allow for fixed auction time and location effects. Numbers in parentheses are robust standard errors clustered at the breeder level. ${ }^{* * *},{ }^{* *}$ and ${ }^{*}$ denote significance at the $1 \%, 5 \%$, and $10 \%$ levels respectively.

Yet we are skeptical that this is the case, for two reasons. First, $X=\$ 20,000$ corresponds to an auction price that is $1 / 3$ greater than the sample median, and thus represents a high threshold for a competitive auction: many multiple-bid auctions are likely to be mis-classified as non-competitive. Second, even at this high threshold, the puzzling prevalence of male buyback under-performance remains - column (4) of Table 14 reveals that the average male buyback shortfall is close to $\$ 15,000$ and is statistically significant at the 
1\% level. Thus, although the auction commission structure may have some explanatory power for buyback under-performance in general, it cannot shed any light on male buyback under-performance.

\section{Concluding Remarks}

Horse breeders surely don't repurchase their own horses with the intention of losing money. Yet the results of this paper indicate this is precisely what happens. Despite having superior information, breeders seemingly make inferior investment decisions. Differences in risk, in abilities, in input quality, and in costs cannot explain or justify this puzzling outcome. Nor can alternative objectives or standard behavioral biases resulting from over-confidence, emotional attachments, or over-exuberance. Adjusting for the true opportunity cost faced by buyback bidders can explain some of the puzzle, but only with an adjustment that almost certainly over-states the case. Most puzzling of all, buyback under-performance is concentrated in male horses, which are primarily purchased for racing (as opposed to breeding) purposes.

It would be interesting to see if a similar phenomenon arises in other common-value auction markets. If so, other researchers may be able to provide an explanation and thus succeed where we have failed. Until then, our results provide a reminder of the traditional folklore claim that a little knowledge can be dangerous. 


\section{References}

Arkes, H., R. Dawes and C. Christensen, 1986. Factors influencing the use of a decision rule in a probabilistic task. Organizational Behavior and Human Decision Processes 37 (1), 93-110.

Barber, B., and T. Odean, 1999. The courage of misguided convictions. Financial Analysts Journal 55 (6), 41-65.

2001. Boys will be boys: gender, overconfidence and common stock investment. Quarterly Journal of Economics 116 (1), 261-292.

Barberis, N. and M. Huang, 2008. Stocks as lotteries: the implications of probability weighting for security prices. American Economic Review 98 (5), 2066-2100.

Bodnaruk, A. and A. Simonov, 2015. Do financial experts make better investment decisions? Journal of Financial Intermediation 24 (4), 514-536.

Bonett, D., 2006. Confidence interval for a coefficient of quartile variation. Computational Statistics \& Data Analysis 50 (11), 2953-2957.

Bonett, D. and E. Seier, 2006. Confidence interval for a coefficient of dispersion in nonnormal distributions. Biometrical Journal 48 (1), 144-148.

Boyer, B., T. Mitton and K. Vorkink, 2009. Expected idiosyncratic skewness. Review of Financial Studies 23 (1), 169-202.

Boyle, G., G. Guthrie and L. Gorton, 2010. Holding onto your horses: conflicts of interest in asset management. Journal of Law and Economics 53 (4), 701-727.

Bulow, J. and J. Roberts, 1989. The simple economics of optimal auctions. Journal of Political Economy 97 (5), 1060-1090. 
Chakraborty, I. and G Kosmopoulou, 2004. Auctions with shill bidding. Economic Theory $24(2), 271-287$.

Chezum, B. and B. Wimmer, 1997. Roses or lemons: adverse selection in the market for thoroughbred yearlings. Review of Economics and Statistics 79 (3), 521-526.

Cochrane, J., Asset Pricing (2nd ed). Princeton University Press.

Daniel, K., D. Hirshleifer and A. Subrahmanyam, 1998. Investor psychology and security market under- and over-reactions. Journal of Finance 53 (6), 1839-85.

DeGennaro, R., 2003. The Utility of Sport and Returns to Ownership. Journal of Sports Economics 4 (2), 145-153.

Dionne, G., M La Haye and A Bergerès, 2015. Does asymmetric information affect the premium in mergers and acquisitions? Canadian Journal of Economics 48 (3), 819-852.

Eberhart, A., 2009. The market for thoroughbred yearlings. Georgetown University. Available at: http://citeseerx.ist.psu.edu/viewdoc/download?doi=10.1.1.720.2198\&rep=rep1\&type=pdf

Fleisig, D., 2011. Adding information may increase overconfidence in accuracy of knowledge retrieval. Psychological Reports 108 (2), 379-92.

Francis, A., 2008. Business Mathematics and Statistics (6th ed.). Cengage Learning EMEA: London.

Gastwirth, J., 1982. Statistical properties of a measure of tax assessment uniformity. Journal of Statistical Planning and Inference 6 (1), 1-12.

1988. Statistical Reasoning in Law and Public Policy, Vol. I. Academic Press: San Diego. 
Gould, W., 2011. Use poisson rather than regress; tell a friend. The STATA Blog. Available at: https://blog.stata.com/2011/08/22/use-poisson-rather-than-regress-tell-a-friend/

Griffin, D., and A. Tversky, 1992. The weighting of evidence and the determinants of confidence. Cognitive Psychology 24 (3), 411-435.

Hall, C., L. Ariss and A. Todorov, 2007. The illusion of knowledge: when more information reduces accuracy and increases confidence. Organizational Behavior and Human Decision Processes 103 (2), 277-290.

Hayward, M., D. Shepherd and D. Griffin, 2006. A hubris theory of entrepreneurship. Management Science 52 (2), 160-172.

Hendricks, K. and R. Porter, 1988. An empirical study of an auction with asymmetric information. American Economic Review 78 (5), 865-883.

Hendricks, K., R. Porter and B Boudreau, 1987. Information, returns, and bidding behavior in OCS auctions. Journal of Industrial Economics 35 (4), 517-542.

Kirkpatrick, A., 2001. Investing in Thoroughbreds: Strategies for Success. Eclipse Press, Lexington, Kentucky.

Knüpfer, S., E. Rantapuska, and M. Sarvimäki, 2017. Formative experiences and portfolio choice: evidence from the Finnish Great Depression. Journal of Finance 72 (1), 133-166.

Kumar, A., J. Page and O. Spalt, 2011. Religious beliefs, gambling attitudes, and financial market outcomes. Journal of Financial Economics 102 (3), 671-708.

Levi, M., K. Li and F. Zhang, 2014. Director gender and mergers and acquisitions. Journal of Corporate Finance 28 (C), 185-200. 
Levitt, S. and C. Syverson, 2008. Market distortions when agents are better informed: the value of information in real estate transactions. Review of Economics and Statistics 90 (4), 599-611.

Lumley, T., P. Diehr, S. Emerson, and L. Chen, 2002. The importance of the normality assumption in large public health data sets. Annual Review of Public Health 23 (October), 151-169.

Merton, R., 1987. A simple model of capital market equilibrium with incomplete information. Journal of Finance 42 (3), 483-510.

Mitton, T. and K. Vorkink, 2007. Equilibrium undiversification and the preference for skewness. Review of Financial Studies 20 (4), 1255-1288.

Olsen, R., 1997, Investment risk: the experts' perspective. Financial Analysts Journal 53 (2), 62-66.

Oskamp, S., 1965. Overconfidence in case-study judgements. Journal of Consulting Psychology $29(3), 261-265$.

Porter, R., 1995. The role of information in U.S. offshore oil and gas lease auctions. Econometrica $63(1), 1-27$.

Santos Silva, J. and S. Tenreyro, 2006. The log of gravity. Review of Economics and Statistics 88 (4), 641-658.

Thaler, R., 1988. The winner's curse. Journal of Economic Perspectives 2 (1), 191-202.

Tsai, C., J. Klayman and R. Hastie, 2008. Effects of amount of information on judgement accuracy and confidence. Organizational Behavior and Human Decision Processes 107 (2), 97-105. 
Wimmer, B. and B. Chezum, 2003. An empirical examination of quality certification in a "lemons market". Economic Inquiry 41 (2), 279-291. 